This document is the Accepted Manuscript version of the following article: Kathleen Lewis and John Tzilivakis, 'The role of the EMA software in integrated crop management and its commercial uptake', Pest Management Science, Vol. 56 (11): 969-973, first published online 13 October 2000. The version of record is available online at doi: DOI: 10.1002/1526-4998(200011). Copyright (C) 2000 Society of Chemical Industry.

Based on a paper presented at the symposium 'The Economic and Commercial Impact of Integrated Crop Management', organised by the $\mathrm{SCl}$ Crop Protection Group in collaboration with the Volcani Center, Israel and the Fresh Produce Consortium and held on 3-4 April 2000 at 14/15 Belgrave Square, London SW1X 8PS, UK. 


\title{
The role of the EMA software in Integrated Crop Management and its commercial uptake
}

\author{
Kathy A Lewis** \& John Tzilivakis
}

Agriculture \& Environment Research Unit, Department of Environmental Sciences, University of Hertfordshire, College Lane, Hatfield, Herts, AL10 9AB.

Abstract: Integrated crop management (ICM) balances the issues of profitability and sustainability with the need for concern for the environment as a whole. As such, it requires sound decision-making based on detailed knowledge of the integrated nature of farming and how any single activity can impact on the business viability (short- and long-term) and on the environment.

This paper reports the development and use of a practical software package (EMA) designed to support farmers, advisers and others in developing ICM practices. An exercise in technology transfer, the package uses a simple, but effective, technique relying on input data and information readily available on farm or that stored in the system's databases. The paper explains how EMA can support ICM, provides an analysis of the identified user-groups and an insight into how the package is being used by these different groups. It also discusses advantages and disadvantages of using software tools in ICM decision making.

\section{INTRODUCTION}

EMA (Environmental Management for Agriculture) is the product of an on-going research and development programme which aims to produce a unified software package to help farmers and their advisers manage the environmental impacts arising from farming practices across the whole farm. The software has been described in detail elsewhere ${ }^{1-3}$ so only a brief summary is provided here. Principally, the software package is an exercise in technology transfer. It is broad-based addressing the farm as an entire process and attempts to bring together the essential information required to minimise environmental impact within a profitable business framework.

\footnotetext{
* Originally presented as a poster presentation at 'The economic and commercial impact of Integrated Crop Management' conference, London April 2000, SCI Crop Protection Group.

${ }^{* \star}$ Correspondence to K A Lewis, Tel: +44 (0) 1707 284582, Fax + 44 (0) 1707 285258, Email:

K.A.Lewis@herts.ac.uk
} 
The software offers a unique approach to agri-environmental protection synthesizing the concepts of formal environmental management systems, such as ISO14001, with the principles of Integrated Crop Management (ICM). The formalised standards adopted by other industries are not sympathetic to the current stressed agricultural industry ${ }^{4}$ being very prescriptive and labour intensive. However, their basic concepts of understanding where negative environmental impacts occur in the process and devising management plans to improve performance, minimising impacts and seeking continuous improvement are sound and equally adaptable to a more informal approach such as that adopted by EMA. ICM is a method of farming that balances the need to run a profitable business with sensitivity to the environment, combining modern technology with basic common sense principles of good farming practice. It is concerned with the development of a whole farm management strategy that recognises the site-specific nature of farming systems.

\section{THE EMA SOFTWARE}

The EMA software allows such a strategy to be devised, the key to its operation being its three main modes of actions. The core of the software is a performance evaluation process (The Evaluation System). This uses an auditing approach to compare actual practices with site-specific best practice to determine a suite of performance indices known as 'eco-ratings'. Eco-ratings are determined for each main farming activity (e.g. crop production, crop protection, resource utilisation, animal husbandry, conservation and soil management) and by comparing these indices, strengths and weaknesses in practices can be identified. This allows areas in need of improvement to be prioritised. The second operational mode is a collection of decision support modules (The Technical System) which enable solutions to the performance weaknesses highlighted during performance evaluation to be identified. It also enables 'what-if' scenarios to be explored. The third operation mode is a comprehensive library (The Advisory System) of information relating to agricultural best practice, applicable legislation and general support literature. Each file is context-sensitively mapped providing a network of hyper-linked documents. 
Each farming activity has one or more elements in each of the three operational modes.

\section{THE ROLE OF EMA IN ICM}

Successful ICM requires farmers to make complex decisions, balancing the issues of profitability and sustainability with specific emphasis on environmental protection, across the whole farm. Sound decision making within such a framework requires a detailed knowledge of the integrated nature of farming and how any single activity can impact on the business viability (both short and long term) and on the environment. Each farm decision needs to be made considering three major objectives: (1) profitable, safe crop production, (2) environmental stewardship and (3) rural protection.

ICM needs to utilise the best available technology with management strategies that are refined and targeted to match the needs of the local site. Access to up-to-date, relevant data and help in its interpretation to turn data into information is vital. EMA seeks to support the decision making process offering cost effective and practicable solutions recognising that economic incentives are imperative to the successful introduction of ICM. Whilst ICM is nonprescriptive in nature there are a number of key areas which need specific attention.

\subsection{Crop nutrition}

The main aim is profitable production of safe, quality food using practices that minimise losses of nutrients to the environment. It requires careful estimation of crop nutrient requirements and accurate application timings to ensure that the nutrients are provided when the crop most needs them. Within the EMA Evaluation System current practices, with respect to total quantities (including that from organic fertilisers and soil conditioners such as those used to adjust $\mathrm{pH}$ and materials used to improve soil structure, water retaining qualities) and timings of $\mathrm{N}, \mathrm{P}$ and $\mathrm{K}$, are compared with site specific fertiliser recommendations provided by a decision support system based upon a standard reference book published by the Ministry of Agriculture, Fisheries and Food (MAFF) ${ }^{5}$. The risk of nutrients losses from runoff are assessed via a risk assessment approach which uses scoring and ranking methods to evaluate practices by comparing these with a site specific description of best practice. A simple heuristical model ${ }^{6}$ embedded in the system provides quantitative estimates of losses 
via leaching considering cultivation practices, crop and soil type. Should the field specific assessment indicate that a problem with practices has been identified then the Technical System can be used to provide fertiliser recommendations from a planning perspective rather than the analytical one used in the Evaluation mode. The differences in the two perspectives being that the Evaluation system retrospectively assess actions already taken providing user feedback on strengths and weaknesses. The Technical system provides a scenario for testing and evaluating potential actions in a risk-free environment in order to seek solutions for the identified problems.

\subsection{Crop protection}

A major aim of ICM is to seek to optimise pesticide use such that losses of pesticides to the environment are minimised and non-target organisms, consumers and farm workers are protected. The software incorporates Advisory, Evaluation and Technical systems and provides a method of helping farmers become less reliant on pesticides by encouraging them to take preventative actions and develop long-term strategies enabling financially viable and environmentally responsible production. It also helps with regulatory compliance and provides assistance in making reasoned assessments as to whether to spray or not and what chemical to use.

The Advisory System provides access to a comprehensive selection of pesticide related literature ${ }^{7,8}$ which includes best practice advice, a database of regulations, help on varietal selection, cultural weed control and strategies for reducing the risk of pesticide resistance. The Evaluation System provides an assessment audit for regulatory compliance and best practice at field level for field / crop applications, other uses (biocides, dips, rodenticides, etc) and general management (waste management, storage, stock control, transport etc). The Technical System provides modules to assist with pesticide choice and best practice. For example, the Pesticide Advisor provides regulatory approval information, cross-linking active substances and mixtures with brand names. Based on crop and pest / disease the module will generate a list of products having regulatory approval for that that particular problem. For each pesticide listed the key label warning phrases of each pesticide are highlighted indicating those that pose a high risk to fish or honeybees. Consequently, the user, with 
knowledge of the application site, is able to select the most appropriate product, for example rejecting those potentially harmful to aquatic life if there is surface water close by. Also embedded into EMA is a large database of pesticide information including Maximum Residue Limits, harvest intervals, maximum number of applications permissible / maximum total dose, tank mix information and off-label approvals.

Unlike most commercially available pesticide databases physical-chemical parameters which affect the environmental fate and so the impact of pesticides (e.g. soil half-life, water solubility, the equilibrium constant for soil organic matter and water $\left(\mathrm{K}_{\mathrm{OC}}\right)$ and the octanolwater partition coefficient $\left(\mathrm{K}_{\mathrm{ow}}\right)$ are stored as well as the source of the data. Bearing in mind the intended end-user this data can be considered highly technical and so the user-interface to the database includes automatic guidance on interpretation and a 'data quality barometer' is used to provide insight into the reliability of the data. A maximum score of 5 points is awarded to data seen to be of the highest quality i.e. that from regulatory sources. Table 1 gives part of a simple example.

Similarly, this database stores ecotoxicological data, both acute and chronic, (where data have been identified) and the data source for a wide range of species (e.g. mammals, fish, higher aquatic plants, algae, honeybees, and earthworms). The database interface also provides interpretation of this data and implements the 'data quality barometer' (Table 1).

Finally, the Technical System includes a Local Environmental Risk Assessment for Pesticides Scheme (LERAPS) implementation module. This was developed in collaboration with Pesticides Safety Directorate and also interacts with the pesticide database simplifying both the assessment and the data recording.

\subsection{Soil management}

EMA includes modules for performance evaluation, management planning and risk assessment of soil fertility, organic fertiliser use, $\mathrm{pH}$ management including lime applications, use of soil conditioners and sewage sludge incorporating the 'Safe Sludge Matrix', soil 
erosion (rainfall and wind) and soil damage. Together these modules seek to protect and conserve soil as a valuable natural resource.

\subsection{Resource management}

Resource efficiency is frequently overlooked when developing ICM management strategies but it can offer key benefits both to the farm through cost savings and to the environment. EMA provides support to ensure efficient use of farm inputs beyond fertilisers and pesticides including energy and water efficiency. The latter covering general farm use and irrigation practices. A waste management module in the Technical System provides up-to-date information on efficient management of all farm wastes including those arising from livestock and crop production, packaging, workshop activities and chemicals. The database follows the principles behind the waste hierarchy - reduction, reuse, recovery, recycling - giving advice on each and finally provides options for approved waste disposal techniques. Emphasis is on waste as a resource throughout.

\subsection{Conservation}

There is extensive information on conservation and biodiversity in the Advisory System ${ }^{10}$. The performance assessment audit is closely linked to the description of the farm and will assess not only current practices but also missed opportunities to improve wildlife habitats and enhance biodiversity.

\subsection{Livestock husbandry}

Although ICM refers specifically to crop production it is often extended to include livestock husbandry (Integrated Farming Systems (IFS)). This is catered for in the software in that it provides regulatory compliance, auditing, management and advisory support for housing, health, welfare and environmental issues associated with beef, dairy, pigs, sheep, goats and poultry. The Advisory System contains several documents relating to livestock welfare ${ }^{11,12}$.

\subsection{Record keeping and traceability}

Comprehensive data recording gives two main benefits. Due of the depth of the detail recorded by the software, it is possible to not only recall the production history of the produce but also to demonstrate justification for the farm decision making. Whilst the original purpose 
of the package was not traceability ${ }^{13}$ it does deal with the issue very effectively. In addition, data files kept over a period of years can be used to monitor performance trends. The main drawback is the length of time required to enter the input data. This can be a lengthy exercise if the farm is large. However, this is helped by a new development which will permit the import-export of data between farm management systems (e.g. CropWalker, Farmade) and EMA. In addition, links with other software decision support systems are also being discussed, as are routines to export the input and assessment data into standard forms that can be Emailed on or can be produced as hardcopy.

\section{DISSEMINATION INTO THE UK AGRICULTURAL INDUSTRY}

The software was released to the industry in 1999 at the low price of $£ 20$, made possible by grant-aid from the UK MAFF. However, although MAFF continue to support the research for the project, a price increase was required in order to finance on-going maintenance and updating of the software, as well as the support service which is offered to users. Research indicated a maximum acceptable price limit of $£ 50$ but the present package, which was released in March 2000, is available for £35+VAT: this is made possible by small grants from a number of major UK agricultural organisations.

Due to demand distribution and promotion has been sub-contracted to other organisations to allow the research team to concentrate on maintenance, updating and new developments.

Initial sales were considerably greater than forecasted. The majority of sales were to advisers $(52 \%)$ as was originally intended. The main surprise was the significant number of farmers (26\%) keen to use the package themselves. Education and policy applications accounted for a further $5 \%$ each and the remaining $12 \%$ were sold to other related sectors e.g. retailers, water companies, conservation bodies. Figure 1 and Table 2 show monthly sales and distribution data, respectively. Although initially developed specifically for England and Wales, there have been significant sales to other parts of the UK and even to Europe and Australia.

\section{THE FUTURE}

EMA-2001 is already under development and will include significant upgrades with respect to the Advisory System, reporting and pesticide risk. With respect to pesticide risk new research 
is underway aiming to improve the crop pesticide audit providing greater harmony with the regulatory risk approach. Other initiatives associated with organic farming and conservation are also in progress.

\section{DISCUSSION}

Many decision support systems have been developed for policy or research purposes and, almost as an afterthought, have been modified for use by farmers. In practice this is rarely successful. One of the major problems is the level of input data required and the complexity of the user-interface. The majority of farmers, and indeed many advisers, have had very little experience of computers and are reluctant to spend time and effort on collating data for software that may or may not provide them with useful information. Similarly, classical type simulation models tend to rely heavily on detailed input data which is often difficult, time consuming and expensive to making them unattractive to many farmers and advisers. EMA uses a simple but effective technique relying on data and information readily available on the farm or that stored in the systems extensive integrated databases.

There is obviously a need for this type of support tool. Successful implementation of ICM requires access to information across many disciplines from ecology and geology to chemistry and environmental science as well as agriculture. It is unreasonable to expect nontechnical end-users to have this information readily available nor will they necessarily know where to obtain it. Systems such as EMA allow large amounts of data to be stored, crossreferenced and managed to allow retrieval on-demand. Considerable attention needs to be applied in order to present the often complex, information in layman terms.

It is important to remember, however, that the information and conclusions provided by such systems should not be presented to the user in a prescriptive manner. Decision-support tools should not be seen as delivering the ultimate advice. Any final decision should be made by the end-user. The software designers need to ensure that the decision making by such systems is transparent. If users are not carefully informed they might be ignorant of the information integrity, unaware of the assumptions and uncertainties embedded within its 
design and so, perhaps, place too high reliance on outputs. These systems should always be used as support tools not replacements for expert advice.

\section{$7 \quad$ CONCLUSION}

EMA is essentially a vehicle for technology transfer and is backed by a team who operate an informal information clearing house so that the software is regularly updated and expanded. It can act equally as a support tool to encourage continuous improvements in and to monitor ICM practices, as an independent management system in partnership with farm assurance schemes or just as an advisory system.

The marketing success has shown that, apart from the very favourable pricing system, farmers have found the system to be very helpful and user-friendly and that it can be used by those with relatively little computing experience.

\section{ACKNOWLEDGEMENTS}

The research and development of the EMA software was originally funded by the Ministry of Agriculture, Fisheries and Food and the Milk Development Council. Dissemination into the industry is supported by a range of organisations from throughout the industry.

\section{REFERENCES}

1 Lewis KA \& Bardon KS, A computer-based informal environmental management system for agriculture, Journal of Environmental Modelling and Software, 13:123-137 (1999).

2 Lewis KA \& Tzilivakis J, Evaluating a technique used to measure environmental performance within agriculture - Case studies, Eco-management and Auditing Journal. 5(3):126-135 (1998).

3 Lewis KA, Tzilivakis J, Skinner JA, Finch J, Kaho T, Newbold MJ \& Bardon KS, Scoring and ranking farmland conservation activities to evaluate environmental performance and encourage sustainable farming, Sustainable Development, 5(2):7178 (1997) 
4 Newbold MJ, Lewis KA, Tzilivakis J, Finch T, Kaho T, Skinner JA \& Bardon KS, The options for informal environmental management: The agricultural industry highlighted, Eco-Management and Auditing Journal, 4(1):22-27 (1997).

5 Ministry of Agriculture, Fisheries and Food (MAFF), Fertiliser Recommendation for Agriculture and Horticulture. 6th Edition, Reference Book RB209, MAFF Publications, London, UK (1994).

6 Lewis KA, Newbold MJ \& Tzilivakis J, Developing an emissions inventory from farm data, Journal of Environmental Management, 55(3):183-197 (1999).

7 Ministry of Agriculture, Fisheries and Food \& the Health and Safety Commission, Code of practice for the safe use of pesticides on farms and holdings. HMSO, London, UK (1990).

8 Crop Protection Association, Practical guides to pesticide stewardship, From CPA, 4 Lincoln Court, Peterborough, PE1 2RP, UK (1998).

9 ADAS, The Safe Sludge Matrix - guidelines for the application of sewage sludge to agricultural land. Advisory booklet from British Agricultural Advisory and Development Service, Ministry of Agriculture, Fisheries and Food, London, UK (1999).

10 Farming and Wildlife Advisory Group (FWAG), Handbook for environmentally responsible farming, FWAG, National Agricultural Centre, Kenilworth, Warwickshire, CV8 2RX, UK (1998).

11 Ministry of Agriculture, Fisheries and Food (MAFF), Codes of recommendations for the welfare of livestock, MAFF Publications, London, UK (1993).

RSPCA, Freedom Foods Welfare Standards, Freedom Food Limited, Causeway, Horsham,West Sussex, RH12 IHG, UK (1998).

Moller Hansen 0, Breembroek JA, Lewis KA \& Janssens SRM, Nutrient recordkeeping and reporting for legislation, crop assurance and traceability, International Fertiliser Society Conference, Robinson College, Cambridge, UK 8-10 December. Proceedings No. 440,ISBN 0853100756 (1999). 


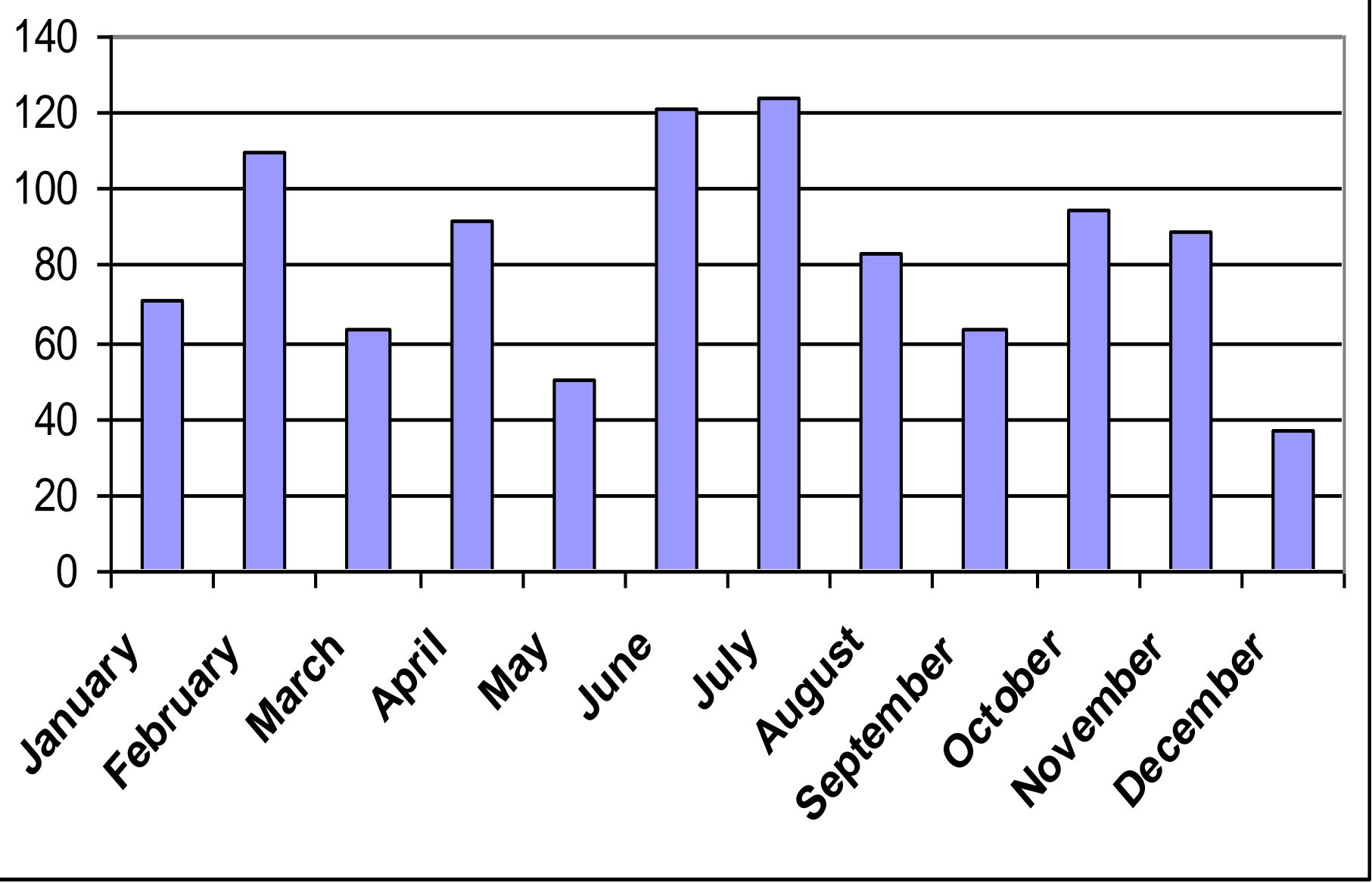




\section{Table 1}

\begin{tabular}{|c|c|c|c|c|}
\hline \multicolumn{5}{|c|}{$\begin{array}{ll}\text { Active Substance: } & \text { Simazine }(1,3,5 \text {-triazine }) \\
\text { CAS reference: } & 122-34-9 \\
\text { WHO Class: } & \text { II } \\
\text { Poison rules apply? } & \text { No } \\
\end{array}$} \\
\hline Parameter & Data value & Source & $\begin{array}{l}\text { Quality } \\
\text { Barometer }\end{array}$ & Interpretation \\
\hline $\begin{array}{l}\text { Water solubility @20C } \\
\left(\mathrm{mg} \mathrm{litre}^{-1}\right)\end{array}$ & 5.0 & $\begin{array}{l}\text { Regulatory } \\
\text { document }\end{array}$ & $5 / 5$ & Low solubility \\
\hline Soil Half-life (days) & 58 & $\begin{array}{l}\text { Regulatory } \\
\text { document }\end{array}$ & $5 / 5$ & Moderately persistent \\
\hline Vapour Pressure (mPa) & $8.10 \mathrm{E}+02$ & $\begin{array}{l}\text { Regulatory } \\
\text { document }\end{array}$ & $5 / 5$ & Volatile \\
\hline $\mathrm{K}_{\mathrm{OC}}\left(\mathrm{ml} \mathrm{g}^{-1}\right)$ & 140 & $\begin{array}{l}\text { US ARS } \\
\text { on-line } \\
\text { database }\end{array}$ & $3 / 5$ & Moderately mobile in soil \\
\hline Log $P$ & 2.3 & $\begin{array}{l}\text { Regulatory } \\
\text { document }\end{array}$ & $5 / 5$ & Low bioaccumulation risk \\
\hline $\begin{array}{l}\text { Acute oral toxicity } \\
\text { mammals } \mathrm{LD}_{50}\left(\mathrm{mg} \mathrm{kg}^{-1}\right)\end{array}$ & 5000 rats & $\begin{array}{l}\text { US } \\
\text { Extoxnet } \\
\text { on-line db }\end{array}$ & $3 / 5$ & Low toxicity \\
\hline $\begin{array}{l}\text { Acute toxicity fish } L^{-1}{ }_{50} \\
\left(\mathrm{mg} \mathrm{kg}^{-1}\right)\end{array}$ & $\begin{array}{l}\text { 2.8 Rainbow } \\
\text { Trout }\end{array}$ & $\begin{array}{l}\text { US } \\
\text { Extoxnet } \\
\text { on-line } \mathrm{db}\end{array}$ & $3 / 5$ & Moderate toxicity \\
\hline $\begin{array}{l}\text { Toxicity Honeybees } L D_{50} \\
\text { (ug per bee) }\end{array}$ & 16 contact & $\begin{array}{l}\text { Pandora } \\
\text { Report }\end{array}$ & $4 / 5$ & Moderate toxicity \\
\hline
\end{tabular}




\section{Table 2}

\begin{tabular}{|c|c|}
\hline Location & \% Total Sales \\
\hline Scotland & $12 \%$ \\
\hline North of England & $10 \%$ \\
\hline Midlands & $23 \%$ \\
\hline West of England & $6 \%$ \\
\hline East of England & $27 \%$ \\
\hline South West & $6 \%$ \\
\hline South East & $9 \%$ \\
\hline Overseas & $7 \%$ \\
\hline
\end{tabular}


Illustration legends

Figure 1 Monthly sales figures for EMA during 1999

Table 1 Example of fate and ecotoxicity data provided in the Pesticide Database

Table 2 Sales of EMA by location 